\title{
Timber: a changing material and its effect on the architectural form
}

\author{
S. Costa Santos \\ University College Dublin, C.E.S.U.G.A., Spain
}

\begin{abstract}
Architects rediscovered timber as a material in the mid 1980s. This renewed interest in timber and its marketing as ecological raw material is related to the increased concern for our planet's ecological balance. Timber, as opposed to steel, glass or reinforced concrete, needs a transformation process with much lower energy consumption. This means that the resource deficit in timber could ultimately translate into an energy deficit. While the availability of good timber for building columns and beams may shrink, the pressure to develop new materials using timber by-products will increase. Supported by the study of architectural examples that show how the more consistent physical properties of the material offer new applications in timber architecture, this work analyses how choosing timber as an ecological material influences the architectural form. Finally, it concludes that the more effective timber-production technology (that minimises the use of energy in manufacturing and assembly) can form the basis for a new form in timber architecture no longer based on the linear member but the panel and can develop new directions in architecture.
\end{abstract}

Keywords: timber architecture, timber technology, timber panel, timber manufacturing methods.

\section{Introduction}

Architects such as Peter Zumthor, Herzog \& de Meuron, and Burkhalter \& Sumi and also the Voralberg school in Austria (especially Baumschlager \& Eberle) rediscovered timber as a material for self-expression in the mid-80s. The renewed interest in timber and its marketing as ecological raw material for the furniture and building industries is a clearly European phenomenon, not only related to the increased concern for our planet's ecological balance. According to 
Christoph Affentranger [1], European forests are underused. They grow, as opposed to any other forests in the world, more timber than is felled. This situation has led in the past twenty years to much political pressure to increase the use of timber from indigenous forests. The increase in the use of petroleum as fuel and the building regulations against designing multi-storey timber dwellings for fire safety reasons after World War II led to a decrease in the demand for the material in Central Europe. The reforestation of Central Europe's forests begun a century ago, leading to a structural problem. The process was carried out planting non-indigenous trees (coniferous as opposed to deciduous) as a monoculture. These forests, over time, become less robust than a mixed forest (with trees of different ages and species) would be. In order to leave them enough room to regenerate, wood from strategically located areas has to be increasingly used. In many different parts of Europe, almost at the same time, actions were taken by the timber industry to increase consumption. Most importantly, the re-evaluation of the material in case of fire was among these actions, because the biggest potential for market growth was seen in the building industry. As a result, the construction of multi-storey dwellings in timber was allowed under certain conditions in Switzerland and some Scandinavian countries after the mid-90s.

But also, timber as ecological raw material is already a structural element. This is the main difference between timber and steel or reinforced concrete. These materials need a transformation process with much higher energy consumption. The fact that steel, glass, concrete and other materials need much more energy means that the resource deficit in timber could ultimately translate into an energy deficit. More effective production methods in the wood industry and innovative, efficient timber materials would help solving the problem of a timber deficit. While the availability of good timber for building columns and beams may shrink, the pressure to develop new materials using timber byproducts will increase. Endless new developments in building systems and timber by-products enter the market on a regular basis. Traditional timber processing requires timber cross sections with a roughly consistent quality. That means that only healthy, straight trunks can be used when producing planks, squared sections and boards. Therefore, offcuts and side boards of lower quality are plentiful. Today, these sections are used, cut down into smaller strips, battens and laminations. The end of this processing chain is represented by chips and sawdust. The process of breaking down into ever smaller pieces is countered by an opposite process: assembly. The smaller the components in the composite products, the more homogeneous their physical properties are. Similarly, the easier it is to influence these properties through the choice of assembly and the choice of binder (chemical or mechanical). Synthetic materials such as adhesive or cement are used to bind chips or sawdust. Strips and laminations are usually glued together, which increases their structural strength.

These facts not only make timber an ecological choice in architecture, but also show how the considerable more consistent physical properties in the material and its by-products (compared to raw timber) are reaching unknown proportions. And, if the new properties of the material can offer new 
applications, the question to answer is: can we influence the architectural form by choosing timber as an ecological material?

\section{Panels}

Today, the timber industry research is directed towards the exhaustive use of the material, including parts that were discarded before, and thus reducing the amount of waste. And within this new direction, the new products and techniques are increasingly being exploited as means of architectural expression. Composite timber products are produced in various processes in which timber of different dimensions (boards, strips, veneers, strands, chips and fibres) is pressed and bonded together using bonding agents or the adhesive properties of timber itself. These manufacturing methods result in a major improvement in quality compared to the source material. That is because defects such as knots, splits or twisted growth can be avoided, giving as a result a product of much greater strength. The processing of timber products follows a downward path with three main stages [2]. The first stage involves making sawn timber like boards and squared timbers, and its most important products are laminated boards. The second stage reduces in size the various off-cuts from the first stage, producing wood strips that are made into multi-layered sheets and high-strength boards. The third stage produces fibreboards from fine waste, pressing it into sheets. In every stage the bonding technology determines the make-up and consistency of the product, making the concept of modelling completely appropriate, because these products are almost entirely susceptible to any attempt to shape them. Timber becomes a strong material that can be freely modelled.

Timber panels are those components made from timber by-products whose structure within the plane of the panel tends to be isotropic, making them directionally neutral and extendable in all directions. In terms of production technology, transport is the only practical limit to their dimensions. Since timber is naturally a directional, or anisotropic, material, this distinction has only become possible due to progress in the manufacture of semi-finished and timberbased products (such as cross-laminated timber panels). The fact that they can span two directions is an important characteristic that determines the design with panels.

Not only the homogeneous inner composition of panels eliminates any recognizable internal hierarchy but also, structurally speaking, panels do not show a hierarchy of primary and secondary elements because they can carry different functions (load-bearing, bracing...). In panelised construction, we can join panels together without a hierarchy that articulates their formal expression. Not only is the structural behaviour of timber architecture modified, but its physical perception too.

Timber panels are multifunctional from both a structural and a constructive point of view. They are synthetic elements: intelligent elements that can solve problems of structure, building physics, weather protection and finishing, and at the same time simplify (reduce) the layered make-up of the element.

Panelised construction distinguishes panels from those composite-section elements that still consist of linear members and whose internal structure does 
not tend to isotropy [3]. Panels consist of three or more layers (usually of relatively low quality wood) arranged at right angles to each other and glued together. They can have a solid or optimised section, and therefore two subcategories can be defined within the field of panelised construction: solid panels and optimised section panels. In order to analyse the influence of timber panels in architecture, various types of panels within these two sub-categories have been studied.

\subsection{Solid panels}

Although these panels use large quantities of timber (such as planks and boards), they are interesting from the ecological point of view because the tree trunk can be used effectively, helping to avoid waste and offcuts. Solid timber elements can form solid wall, floor or roof elements (by simply using metal or wood connectors or adhesive bonding) and assume load-bearing, bracing, insulating and sealing functions. That involves a great simplification in the build-up of layers. In timber frame construction, for instance, internal wall surfaces are often lined with plasterboard that is then filled, smoothed and painted. Today's solid panels are the result of different techniques that can achieve different levels of quality, retaining the surface character and structural features of timber, in particular the grain. Thus, when using these systems with a visible wood surface, further finishes are not necessary. Today, subsequent heat or oil-and-heat treatments make timber more resistant to weathering as well, allowing the structural panel to become external cladding. That means that they are both constructive and structurally multifunctional. The most important types of solid timber panels are: cross-laminated panels, solid panels made with composite boards and panels made with stacked boards planks.

The formal language derived from the use of solid timber panels doesn't have to follow a modular design because these constructive elements can be manufactured in big sizes without following a given module. Their homogeneous and compact inner structure allows flexible cutting of the openings, without additional elements around the perimeter, and means that loads and supports can be placed with few limitations, making these components easy to be modified or adjusted on site. These characteristics can affect the way architectural form is understood, as the project of the Holy Family Nursery in Eichstätt (Germany), designed by Karl Frey, shows. The building uses cross-laminated timber panels to resolve the structure and define the different spaces. The fact that the same element can have several structural and enclosing functions (that is, for instance, working either as a vertical or a horizontal plane) avoids the need for formal articulation between elements. At the same time, that increases the flexibility of the constructive system. The Nursery shows how solid panels can freely include openings without any additional structural elements. This fact could, ultimately, challenge the visual integrity of the plane. Solid panels also revise the limit state of the raw material, because the internal structure of timber is overcome and its dimensional order increases. At the same time, the length of the joint decreases. On-site construction is not based on joining linear elements but on the assembly of surfaces, in other words, the design unit of the Holy Family Nursery is not an 


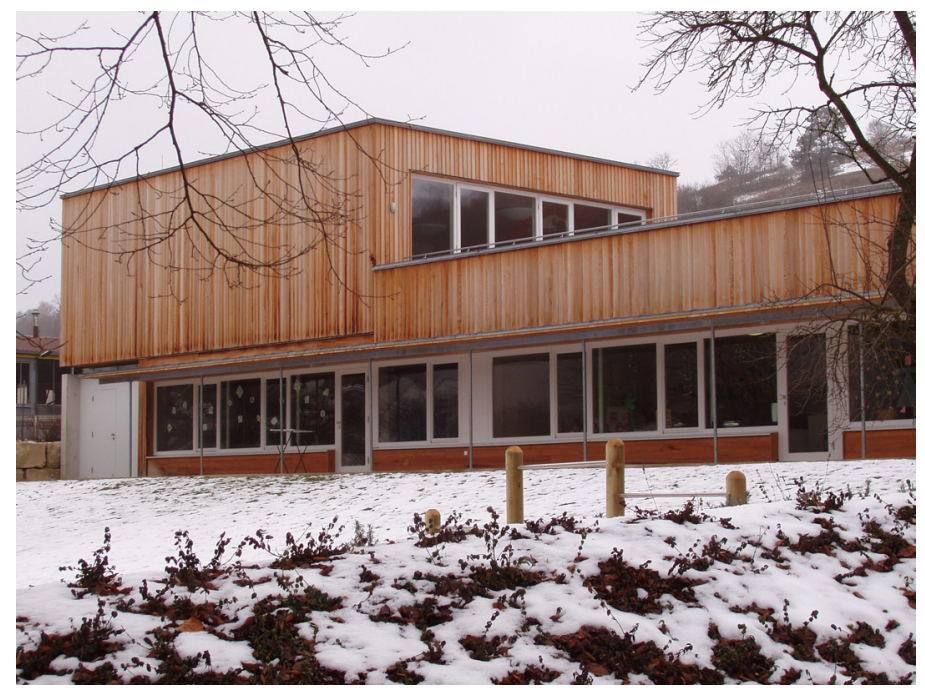

Figure 1: Holy Family Nursery, Eichstätt.
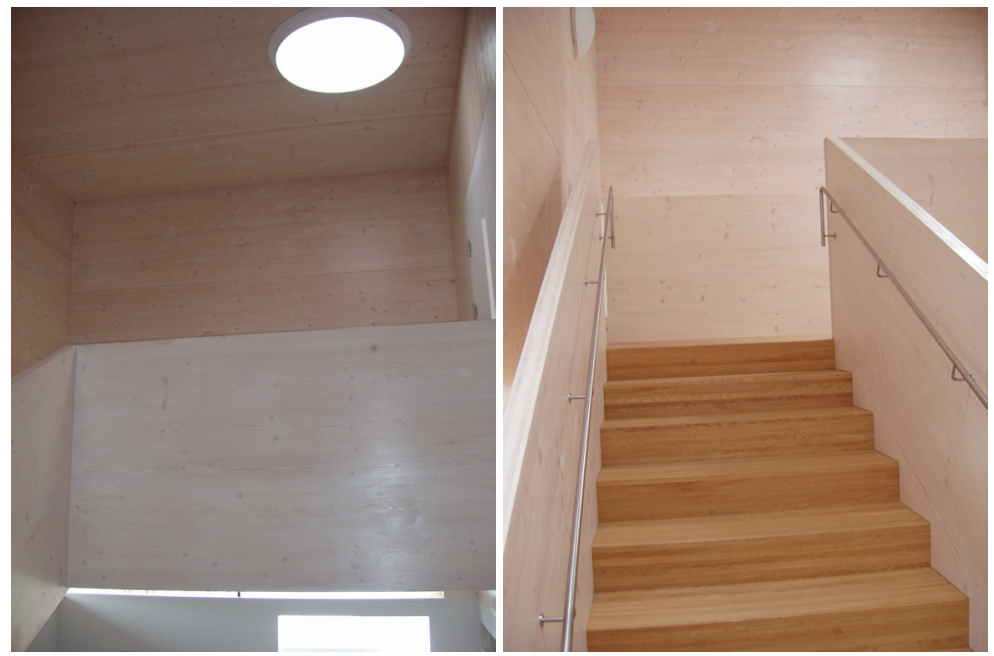

Figure 2: Holy Family Nursery: cross-laminated timber panels.

ideal linear form but a surface that could be extended ad infinitum; its exposed continuous surfaces can trigger formal possibilities not necessarily related to the linear element but to the surface element.

\subsection{Optimised section panels}

Composite panels rely on the optimisation of the section once a certain panel thickness has been achieved. They are generally made up with two boards and an 
inner structure to which they are bonded. Although their inner structure, with ribs and cross-ribs, is not homogeneous, it tends towards isotropy. This internal build-up of the panel dictates where loads, supports and cuts should be located. However, this inner structure is easily modified in the workshop to suit different situations: there is much scope for flexibility within the internal layer, where the cavities can be filled with insulation or used to conduct services, thus making complete constructive units. The same as solid panels, optimised section panels are synthetic (multifunctional) elements. There are many types of optimised section panels: structural insulated panels (SIP); box, ribbed or hollow section panels; folded panels and board-system panels.

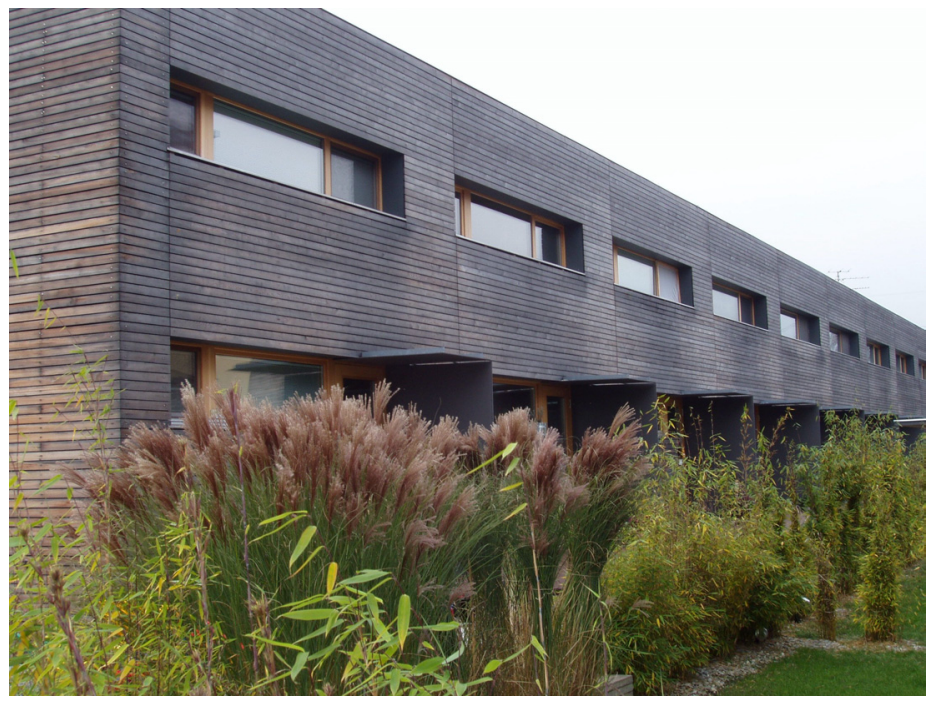

Figure 3: Passive-Energy housing in Dornbirn.
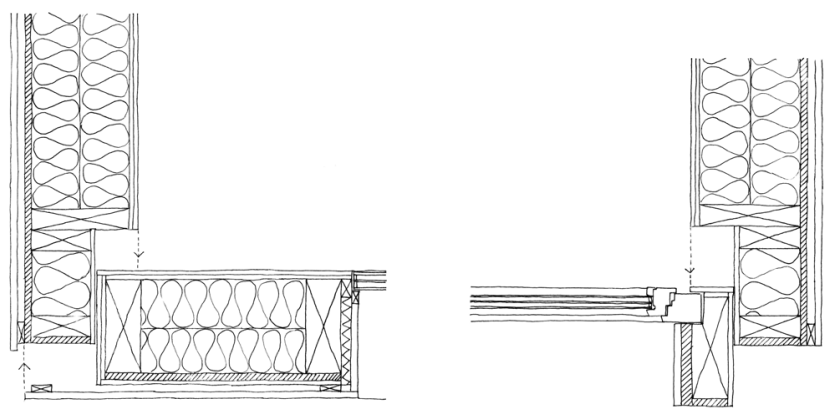

Figure 4: Assembly joints between panels (Passive-Energy housing in Dornbirn). 
Using optimised timber panels may also involve re-thinking the traditional language of timber architecture. Their non-homogeneous inner structure allows placing cuts virtually anywhere in their surface, as long as their perimeter is occupied by ribs. This fact makes cuts and openings less limited in size than in the case of solid panels. They can be freely manufactured without following a module, although they should not be adjusted on site but treated as finished elements. This process of re-thinking the traditional envelope involved in using these panels is clearly shown in the Passive-Energy housing in Dornbirn, designed by the architect Johannes Kaufmann. The project's walls use prefabricated timber box section structural elements. In this scheme consisting of a row of nine terraced houses with a communal unit at the end, the use of these prefabricated timber elements ensured, according to the architect, low production costs and a short construction period [4]. All the units were erected in a dry form of construction, as completely finished prefabricated synthetic components: the $28 \mathrm{~cm}$ thick panels are fully insulated and include door and window openings. They were just clad to the outside with larch boarding on site. We can see in this example how the space-making process of traditional architectural form (based on several stages and layers) is hugely simplified. The space-defining role of the structure, the enclosing of the interior space by material planes, the establishment of an immediate relationship with the exterior space by the opening, and the symbolic meaning expressed by the cladding are all simultaneous actions. At the same time, this relationship between interior and exterior space has flexibility due to the structural characteristics of the panel.

\section{Conclusion}

The fact that other materials need much more energy consumption during production than timber demands more effective production methods in the wood industry to avoid a resource deficit that could ultimately translate into an energy deficit. More effective manufacturing methods use timber of various dimensions and offcuts, avoiding defects and thus giving as a result increasingly strong and slender materials. The most innovative elements produced with these methods are the sheets or panels.

The panel becomes the basic element of contemporary timber architectural form and replaces the traditional linear element. Then, three major design changes follow the use of prefabricated timber panels in architecture: the elements become multifunctional, they can work structurally in two directions, and they can be prefabricated as surface components in a non modular way. In other words, the multifunctional non-modular panel becomes the new design unit of timber architectural form, and can develop new directions in architecture because it follows a different set of criteria when defining the spatial envelope, and, therefore, when creating architectural space.

Finally, we can conclude that a more effective timber-production technology can lead to a new form in timber architecture no longer based on the linear member but the panel, opening new directions in architecture. 


\section{References}

[1] Affentranger, Ch., Building with wood: between sense and sensitivity. Tendencies in modern timber building methods. $A+U$ 02:06 no. 381 pp. $78-$ 84, 2002.

[2] Deplazes, A., Wood: indifferent, synthetic, abstract - man-made. Werk, bauen + wohnen 1-2, pp. 78-81, 2001.

[3] Merz, Ch. Personal Communication, 24 November 2005, Kaufmann-Merz Engineering, Dornbirn, Austria.

[4] Kaufmann, J. Personal Communication, 24 November 2005, Johannes Kaufmann Architect, Dornbirn, Austria. 